\title{
A fenugreek seed extract selectively reduces spontaneous fat intake in overweight subjects
}

Hugues Chevassus ${ }^{1,2}$, Jean-Baptiste Gaillard ${ }^{3}$, Anne Farret ${ }^{1,2}$, Françoise Costa ${ }^{1,2}$, Isabelle Gabillaud ${ }^{1,2}$, Emilie Mas $^{3}$, Anne-Marie Dupuy ${ }^{3}$, Françoise Michel $^{3}$, Caroline Cantié1 ${ }^{1,2}$, Eric Renard ${ }^{4,5}$, Florence Galtier ${ }^{1,2,5}$, Pierre Petit $^{1,2,5}$.

${ }^{\left({ }^{()} C H R U\right.}$ Montpellier, Centre d'Investigation Clinique, Montpellier, France

${ }^{(2)}$ INSERM, CIC 0001, Montpellier, France

${ }^{(3)}$ CHRU Montpellier, Laboratoire de Biochimie, Montpellier, France

${ }^{(4)}$ CHRU Montpellier, Service des Maladies Endocriniennes, Montpellier, France

${ }^{(5)}$ Université Montpellier I and CNRS UMR 5232, Centre de Pharmacologie et Innovation dans le Diabète, Montpellier, France

Corresponding author: Hugues Chevassus, h-chevassus@chu-montpellier.fr

Centre d'Investigation Clinique INSERM-CHRU, Hôpital Saint-Eloi, 80 avenue Augustin Fliche, 34295 Montpellier Cedex 5, France

Telephone number: +33(0)4 $67332325 \quad$ Fax number: +33(0)4 67332335

Keywords: eating behaviour, energy intake, fat, fenugreek seed, overweight subjects, human

Word count: 3056 (main text) / 245 (abstract)

Number of tables: 2 / Number of figures: 1 


\section{Abstract}

Purpose - Fenugreek seeds (Trigonella foenum-graecum L.) have long been used as herbal medicine for metabolic and nutritive dysfunctions. They were shown to modulate feeding behaviour in animals. We have recently observed a selective decrease in fat consumption in normal weight healthy volunteers after treatment by a hydro-alcoholic seed extract. However, strong clinical data about the effects of fenugreek seeds on energy intake is lacking, especially in overweight individuals. The present study aimed at investigating the effects of a repeated administration of a fenugreek seed extract on eating behaviour in overweight subjects.

Methods - Thirty-nine overweight healthy male volunteers completed a 6-week double-blind randomized placebo-controlled parallel trial of a fixed dose of a fenugreek seed extract. Main endpoints were energy intake (dietary records and meal test), weight, fasting and post-absorptive glucose and insulin, appetite/satiety scores and oxidative parameters.

Results - Daily fat consumption, expressed as the ratio fat reported energy intake / total energy expenditure (fatREI/TEE) was significantly decreased by the fenugreek seed extract in overweight subjects (fat-REI/TEE: $0.26 \pm$ 0.02 vs $0.30 \pm 0.01 ; P=0.032$ ). We also observed a significant decrease of the insulin/glucose ratio in the subjects treated with fenugreek seed extract $(0.89 \pm 0.09$ vs $1.06 \pm 0.10 \mathrm{mUI} / \mathrm{mmol} ; P=0.044)$. No significant effect was observed concerning weight, appetite/satiety scores, or oxidative parameters.

Conclusion - The repeated administration of a fenugreek seed extract slightly but significantly decreased dietary fat consumption in healthy overweight subjects in this short-term study. 


\section{Introduction}

Fenugreek (Trigonella foenum-graecum L.) is an herbaceous annual plant from the family of Leguminosae, cultivated in Mediterranean countries and India. Its seeds have been known for a long time as herbal medicine for various pathological conditions. A number of pharmacological and clinical studies have shown glucose and lipid lowering properties of either the seed itself, seed extracts or purified components (see [1] for review). In addition, antioxidant properties have been observed in animal studies [2, 3].

Fenugreek-based preparations are used in humans to stimulate appetite and promote weight gain [4]. However, these properties are supported only by animal data, which show some inconsistencies. We have previously demonstrated that a repeated administration of a hydro-alcoholic seed extract enhanced motivation to eat and food consumption in rats, with a slight weight increase [5]. Appetite and food intake were also increased by a subchronic treatment with a purified steroid saponin fraction from the seed, with a modified circadian rhythm of feeding behaviour [6]. In contrast, in a safety study using a dietary supplement with fenugreek seeds in animals [7], no effect was observed on food consumption. More recently, it was found that a fenugreek seed extract reduced the body weight gain induced by a high-fat diet in obese mice [8]. However, no clinical data on body weight and food intake was available since our recent report showing a reduction of fat consumption in freeliving conditions in healthy normal weight volunteers, after a 14-day repeated administration of a fenugreek seed extract [9].

As the latter property could be of interest in overweight subjects, we undertook the present study to investigate the effects of this fenugreek seed extract on fat intake in overweight patients. Secondary objectives included weight, glycaemia, plasma insulin, lipid profile, as well as oxidative stress and antioxidant capacities, which improvements with fenugreek seeds have been demonstrated in animals, but never shown in humans.

\section{Materials and methods}

\section{$\underline{\text { Study design }}$}

The study was designed as a 6-week double-blind randomized placebo-controlled parallel trial.

\section{$\underline{\text { Subjects }}$}

Thirty-nine healthy overweight male volunteers, aged 18-59 years (mean: 38 years), completed this study. All were of stable weight (mean weight: $85.4 \mathrm{~kg}$; range: $75.2-105.5$; mean body mass index: $27.3 \mathrm{~kg} . \mathrm{m}^{-2}$; range: 
24.9-29.4). One subject of the 40 included was withdrawn of the study before the first experimental drug administration because of the consumption of a non-authorized treatment.

\section{Ethical aspects}

This study was approved by the Ethics Committee "Comité de Protection des Personnes Montpellier-Saint-Eloi" and conducted in accordance with the Helsinki declaration and the ICH guideline for Good Clinical Practice. All the subjects gave written informed consent to participate.

\section{Test compound}

The test compound was a marketed dry hydro-alcoholic fenugreek seed extract administered three times daily as oral coated tablets coming from the batch used in our previous study conducted in healthy normal weight volunteers [9]. The total daily dose of $1176 \mathrm{mg}$ (approximately $14 \mathrm{mg} \cdot \mathrm{kg}^{-1}$ ) is the double of the extract's daily dose commonly prescribed in human. It was selected because it appeared to be the active dose in healthy volunteers [9]. This dose is also in accordance with the two active doses used in the animal study testing the same extract [5], corresponding to 5 and $53 \mathrm{mg} \cdot \mathrm{kg}^{-1}$ human equivalent doses. The extract contained diosgenine, steroid saponins, $1.38 \%$ trigonelline and $1.50 \%$ 4-hydroxyisoleucine, as characterized by thin-layer chromatography and high performance liquid chromatography. Placebo tablets were manufactured using the same excipients, the same process and the same packaging as for active tablets making them indistinguishable. The similarity between the seed extract and the placebo tablets was verified on 5 criteria (aspect, size, weight, colour and smell).

\section{Investigations}

Diet and physical activity were assessed in free-living conditions before and at the end of the ambulatory treatment period, using a 7-day record, accurately reviewed by a trained dietician and a physician. Reported energy intake (REI) was determined with Enkal-Pro ${ }^{\circledR}$ software (Loging Software, Lille, France). Total energy expenditure (TEE) was calculated as basal metabolic rate (BMR) multiplied by physical activity level (PAL) according to Black et al [10]. Energy intake was expressed as the ratio REI/TEE. Underreporting was defined as a ratio $\mathrm{REI} / \mathrm{BMR}<1.1[11]$

The day following the first 7-day record completion, subjects attended the study centre for a baseline visit in fasting condition. Body weight was recorded while the subjects were dressed in underwear and after they had 
urinated, using the same balance Seca ${ }^{\circledR} 861$ (Seca, Hamburg, Germany) with an accuracy of \pm 0.1 g. Body composition was measured by a multi-frequency bioelectrical impedance analysis. Blood was drawn and urine was collected for determination of plasma glucose, serum insulin and lipid profile, oxidative stress and antioxidant capacities. They were then discharged and treatment was taken ambulatory. During the last week of treatment, subjects completed a second 7-day record, and then attended the study centre after an overnight fast for their final visit, which comprised all the baseline evaluations. In addition, they had to consume completely in a maximum of 30 min a standardized breakfast (13\% protein, $35 \%$ fat, $52 \%$ carbohydrate) providing $20 \%$ of their daily energy requirements, and to describe their appetite, satiety and palatability feelings on visual analogue scales $[12,13]$ before and every $30 \mathrm{~min}$ for $270 \mathrm{~min}$ after starting eating breakfast. At 12:30 a.m., they were served an ad libitum mixed meal consisting of 13\% protein, $35 \%$ fat, $52 \%$ carbohydrate, and the amount of food ingested was weighed with an accuracy of $\pm 0.1 \mathrm{~g}$.

\section{$\underline{\text { Analytical methods }}$}

Plasma glucose was assayed by the glucose oxidase method. Serum insulin was measured by RIA (BI-INSULIN IRMA, CIS Bio-international, Gif-sur-Yvette, France). Serum triglycerides, total cholesterol and high-density lipoprotein (HDL)-cholesterol were assayed with an enzymatic method (lipase/glycerokinase, cholesterol oxidase and cholesterol oxidase after separation respectively).

Antioxidant parameters were total plasma antioxidant capacity (quantitative colorimetric technique), low density lipoproteines (LDL) susceptibility to oxidation, serum and LDL vitamin E (HPLC), and plasma vitamin C (HPLC). LDL were obtained by plasma sequential ultracentrifugation with a potassium bromide-adjusted density of 1.063. LDL oxidation was initiated with Copper [Cu (II), $5 \mu \mathrm{M}]$ and continuously monitored during 6 hours by measuring the increase in absorbance at $234 \mathrm{~nm}$ due to conjugated diene formation. LDL susceptibility to oxidation was expressed by the reaction lag phase time, the maximal propagation rate, the time of half oxidation and the slope of the propagation phase. Oxidative stress was assessed by plasma malonyldialdéhyde [14], plasma advanced oxidation protein products [15], plasma advanced glycation end products (fluorescence spectroscopy) and the urinary ratio free 8 -iso $\mathrm{PGF}_{2}(\mathrm{LC}-\mathrm{MS} / \mathrm{MS}) /$ creatinine.

\section{Data analysis and statistics}

The sample size ( 40 subjects to be enrolled in 2 groups of 20) was calculated using data obtained in our previous study [9], with an expected mean difference for energy consumption (main outcome) between fenugreek seed 
extract and placebo of $216 \mathrm{kcal}$ per day, a common SD of $238 \mathrm{kcal}$ par day, a two-sided alpha of 0.05 and a statistical power of $80 \%$.

Results are expressed as the mean \pm standard error of the mean (SEM). 95\% Confidence intervals for the differences $(95 \% \mathrm{CI})$ are given where necessary.

Means were compared using analysis of covariance (ANCOVA) with baseline data as covariate, after logarithmic transformation if necessary. Non parametric data were compared using the Mann-Whitney test. Calculations and statistical analysis were performed using the Systat ${ }^{\circledR} 10.0$ software for Windows $^{\circledR}$ (SPSS, Chicago, IL). The level of significance was set at $\mathrm{P}<0.05$.

\section{Results}

Underreporting was similar between fenugreek and placebo groups (38.9\% (7/18) vs 40\% (8/20), NS). As a result, total-REI was lower than daily TEE in both groups (basal ratio total-REI/TEE: $0.74 \pm 0.05(\mathrm{n}=18)$, and $0.73 \pm 0.03(\mathrm{n}=20)$ respectively, NS). At baseline, macronutrient intake was similar between fenugreek and placebo groups (Figure 1, panel A). After 6 weeks of treatment with the fenugreek seed extract, a significant decrease in TEE-adjusted reported fat intake was observed (post treatment fat-REI/TEE: $0.26 \pm 0.02(\mathrm{n}=18) v \mathrm{~s}$ $0.30 \pm 0.01(\mathrm{n}=20), P=0.032)$, while protein and carbohydrate intakes were not significantly modified (Figure 1, panel B). Total-REI was not significantly modified by the treatment (post treatment total-REI/TEE: $0.68 \pm$ $0.05(\mathrm{n}=18)$ vs $0.73 \pm 0.03(\mathrm{n}=20), \mathrm{NS})$. Spontaneous food intake during the ad libitum meal test, weight, body composition, appetite and satiety scores did not differ between treated and untreated subjects.

The main biological parameters are described in tables I and II. The ratio of fasting serum insulin/plasma glucose was significantly decreased in subjects treated with fenugreek seed extract $(0.89 \pm 0.09(\mathrm{n}=19) v s 1.06 \pm 0.10(\mathrm{n}$ = 19) mUI.mmol $\left.{ }^{-1}, P=0.044\right)$ (Table I). No effect on plasma lipid profile (Table I), antioxidant parameters and oxidative stress markers (Table II) could be observed.

No serious adverse events occurred. Among the 35 non serious adverse events reported (17 with fenugreek, 18 with placebo), only 5 might be related to the experimental treatment: 4 cases of mild gastro-intestinal symptoms and 1 case of specific urine and sweat smell.

\section{Discussion}

The present report shows for the first time that a treatment with a fenugreek seed extract selectively reduces spontaneous fat consumption in overweight male subjects. We also show that the fenugreek seed extract does not 
increase food consumption. This latter result differs from the traditional use of fenugreek-based preparations for appetite stimulation and weight gain [4]. It also contrasts with our previous observations of enhanced food consumption in animals treated by a hydro-alcoholic crude extract or a purified steroid saponin fraction $[5,6]$. However, this observation is in accordance with the results of our previous investigation in normal weight healthy subjects [9].

This effect has been observed with a reliable evaluation of energy intake in free-living conditions i.e. baseline and post-treatment 7-day records, adjustment on physical activity, systematic dietician review. While selfreported dietary records may underreport energy intake, they remain an important tool for nutrition researchers and a record of 7 consecutive days is considered reliable to quantify diet for outpatients [16]. As expected in an overweight population [17], underreporting of energy intake was frequent $(\approx 40 \%)$, but similar in treated and control groups, which were initially comparable.

The effect on fat consumption could not appear in standardized conditions because the meal test used was composed of a single course that didn't allow any dietary choice.

Such a specific effect, without any significant change in the intake of other nutrients, and without any alteration of appetite or palatability, has already been observed in pharmacological studies undertaken in rats by activation of the hypothalamic serotonin pathway [18], and in human after a methylphenidate challenge activating the brain dopamine pathway by blocking its reuptake [19].

The moderate magnitude of this effect $(-10 \%)$ made it unlikely to induce a decrease in weight over short periods, and indeed we did not observe any modifications in body weight or body composition. It is also worthy to notice that no significant change in body weight was observed by Sharma et al. [20] in a clinical study evaluating the safety of fenugreek seeds consumed in diabetic patients, although their study was not designed to assess eating behaviour or weight modifications. Nevertheless, it can be hypothesized that fenugreek seed extract may favour a weight reduction in the long term, particularly in overweight or obese patients for whom a low-fat diet is recommended, and thus improve the metabolic status of these subjects.

The lower ratio of fasting serum insulin/plasma glucose may reflect an improved insulin sensitivity, as previously described with fenugreek seed preparations in type 2 diabetes [21]. This effect may be related to 4hydroxyisoleucine, an amino acid present in fenugreek seeds, known for its insulin-sensitizing effect [22]. However, even if this biological mechanism would support the hypothesis of an improved insulin sensitivity in our sample, fasting glucose and insulin values (and related calculated indexes) are insufficient to draw such a conclusion, and specific investigations such as clamp studies would be required. As fenugreek is traditionally 
used to treat type 2 diabetic patients in Mediterranean and Asian countries, our results provide a rationale for conducting further research on the potential usefulness of fenugreek in disorders of carbohydrate metabolism.

In spite of an extensive exploration, we observed no significant effect on plasma antioxidant capacity or oxidative stress, which were ancillary biological objectives. This result is in contrast with previously reported data in rats [2] and mice [3]. This might be related to our experimental conditions. First, our population was characterized by a normal baseline oxidative/antioxidant profile, and antioxidant properties are easier to detect in conditions of increased oxidative stress. Second, our sample size may have been insufficient to show a significant difference on these parameters. Alternatively, it is possible that the antioxidant properties shown in animal studies are not present in human.

Finally, it has to be noticed that the treatment with the fenugreek seed extract did not modify the subjects' lipid profile, which also may be explained by the healthy status of the subjects.

Although fenugreek seed extract is coloured and displays a specific smell, active and placebo tablets could not be identified by the investigators and the subjects, thanks to the coating process making them indistinguishable. Nevertheless, one subject detected an unusual smell in his urine and sweat during the treatment period without having expressly been interpreted as treatment-related. This unique case of possible identification of the treatment received by the subject did not conduct to any de-blinding for the rest of the volunteers. Considering this problem, the occurrence of de-blinding has to be systematically tested in clinical studies investigating fenugreek seed preparations.

\section{Conclusion}

The repeated administration of a fenugreek seed extract slightly but significantly decreased dietary fat consumption in human in this short-term study; this new property, together with a potential favourable effect on insulin sensitivity, may be helpful in subjects who need to decrease their fat intake, and may improve the metabolic status of overweight subjects. The fenugreek seed's component(s) involved and the mechanism(s) of this effect remain to be elucidated. 


\section{Acknowledgements}

This study was sponsored by the University Hospital of Montpellier (UF7698) with the financial support of French Ministry of Health (PHRC régional 2001) and Laboratoires Legras (Cachan, France).

We specially thank B Bories-Azeau (administrative assistant) for her extensive work concerning volunteers recruitment and study management.

This study was also successfully carried out thank to the expert scientific, medical, technical and logistic assistance of JL Allaz, AM Barbanel, R Blanc, A Bonardet, A Cadène, JP Cristol, M Escoffier, J Foppolo, P Jonquet, C Montaudié, A Mouraret, C Piat, MC Picot, G Pouly, AM Puech-Cathala, I Roch-Torreilles, MH Rocolle and H Tsiambakaïna. 


\section{References}

1. Sauvaire Y, Petit P, Baissac Y, Ribes G (2000) Chemistry and pharmacology of fenugreek. In: Mazza G, Oomah BD (ed) Herbs, botanicals and teas, Technomic Publishing, Lancaster, USA, pp 107-129

2. Ravikumar P, Anuradha D (1999) Effect of fenugreek seeds on blood lipid peroxidation and antioxidants in diabetic rats. Phytotherapy research 13:197-201

3. Choudhary D, Chandra D, Choudhary S, Kale RK (2001) Modulation of glyoxalase, glutathione Stransferase and antioxidant enzymes in the liver, spleen and erythrocytes of mice by dietary administration of fenugreek seeds. Food Chem Toxicol 39:989-997

4. Rguibi M, Belahsen R (2006) Body size preferences and sociocultural influences on attitudes towards obesity among Moroccan Sahraoui women. Body Image 3:395-400

5. Petit P, Sauvaire Y, Ponsin G, Manteghetti M, Fave A, Ribes G (1993) Effects of a fenugreek seed extract on feeding behaviour in the rat: metabolic-endocrine correlates. Pharmacol Biochem Behav 45:369-374

6. Petit PR, Sauvaire YD, Hillaire-Buys DM, Leconte OM, Baissac YG, Ponsin GR, Ribes GR (1995) Steroid saponins from fenugreek seeds: extraction, purification, and pharmacological investigation on feeding behavior and plasma cholesterol. Steroids 60:674-680

7. Udayasekharan Rao P, Sesikeran B, Srinivasa Rao P, Nadamuni Naidu A, Vikas RV, Ramachandran EP (1996) Short term nutritional and safety evaluation of fenugreek. Nutrition Research 16:1495-1505

8. Handa T, Yamaguchi K, Sono Y, Yazawa K (2005) Effects of fenugreek seed extract in obese mice fed a high-fat diet. Biosci Biotechnol Biochem 69:1186-1188

9. Chevassus H, Molinier N, Costa F, Galtier F, Renard E, Petit P (2009) A fenugreek seed extract selectively reduces spontaneous fat consumption in healthy volunteers. Eur J Clin Pharmacol In press

10. Black AE, Coward WA, Cole TJ, Prentice AM (1996) Human energy expenditure in affluent societies: an analysis of 574 doubly-labelled water measurements. Eur J Clin Nutr 50:72-92

11. Goldberg GR, Black AE, Jebb SA, Cole TJ, Murgatroyd PR, Coward WA, Prentice AM (1991) Critical evaluation of energy intake data using fundamental principles of energy physiology: 1. Derivation of cut-off limits to identify under-recording. Eur J Clin Nutr 45:569-581

12. Hill AJ, Magson LD, Blundell JE (1984) Hunger and palatability: tracking ratings of subjective experience before, during and after the consumption of preferred and less preferred food. Appetite 5:361-371

13. Raben A, Tagliabue A, Astrup A (1995) The reproducibility of subjective appetite scores. Br J Nutr 73:517530 
14. Yagi K (1976) A simple fluorometric assay for lipoperoxide in blood plasma. Biochem Med 15:212-216

15. Witko-Sarsat V, Gausson V, Nguyen AT, Touam M, Drueke T, Santangelo F, Descamps-Latscha B (2003) AOPP-induced activation of human neutrophil and monocyte oxidative metabolism: a potential target for Nacetylcysteine treatment in dialysis patients. Kidney Int 64:82-91

16. Jackson B, Dujovne CA, DeCoursey S, Beyer P, Brown EF, Hassanein K (1986) Methods to assess relative reliability of diet records: minimum records for monitoring lipid and caloric intake. J Am Diet Assoc $86: 1531-1535$

17. Johansson L, Solvoll K, Bjorneboe GE, Drevon CA (1998) Under- and overreporting of energy intake related to weight status and lifestyle in a nationwide sample. Am J Clin Nutr 68:266-274

18. Smith BK, York DA, Bray GA (1999) Activation of hypothalamic serotonin receptors reduced intake of dietary fat and protein but not carbohydrate. Am J Physiol 277:R802-811

19. Goldfield GS, Lorello C, Doucet E (2007) Methylphenidate reduces energy intake and dietary fat intake in adults: a mechanism of reduced reinforcing value of food? Am J Clin Nutr 86:308-315

20. Sharma RD, Sarkar A, Hazra DK, Misra B, Singh JB, Maheshwari BB (1996) Toxicological evaluation of fenugreek seeds: a long term feeding experiment in diabetic patients. Phytotherapy research 10:519-520

21. Madar Z, Abel R, Samish S, Arad J (1988) Glucose-lowering effect of fenugreek in non-insulin dependent diabetics. Eur J Clin Nutr 42:51-54.

22. Broca C, Breil V, Cruciani-Guglielmacci C et al (2004) Insulinotropic agent ID-1101 (4-hydroxyisoleucine) activates insulin signaling in rat. Am J Physiol Endocrinol Metab 287:E463-471 
Table I

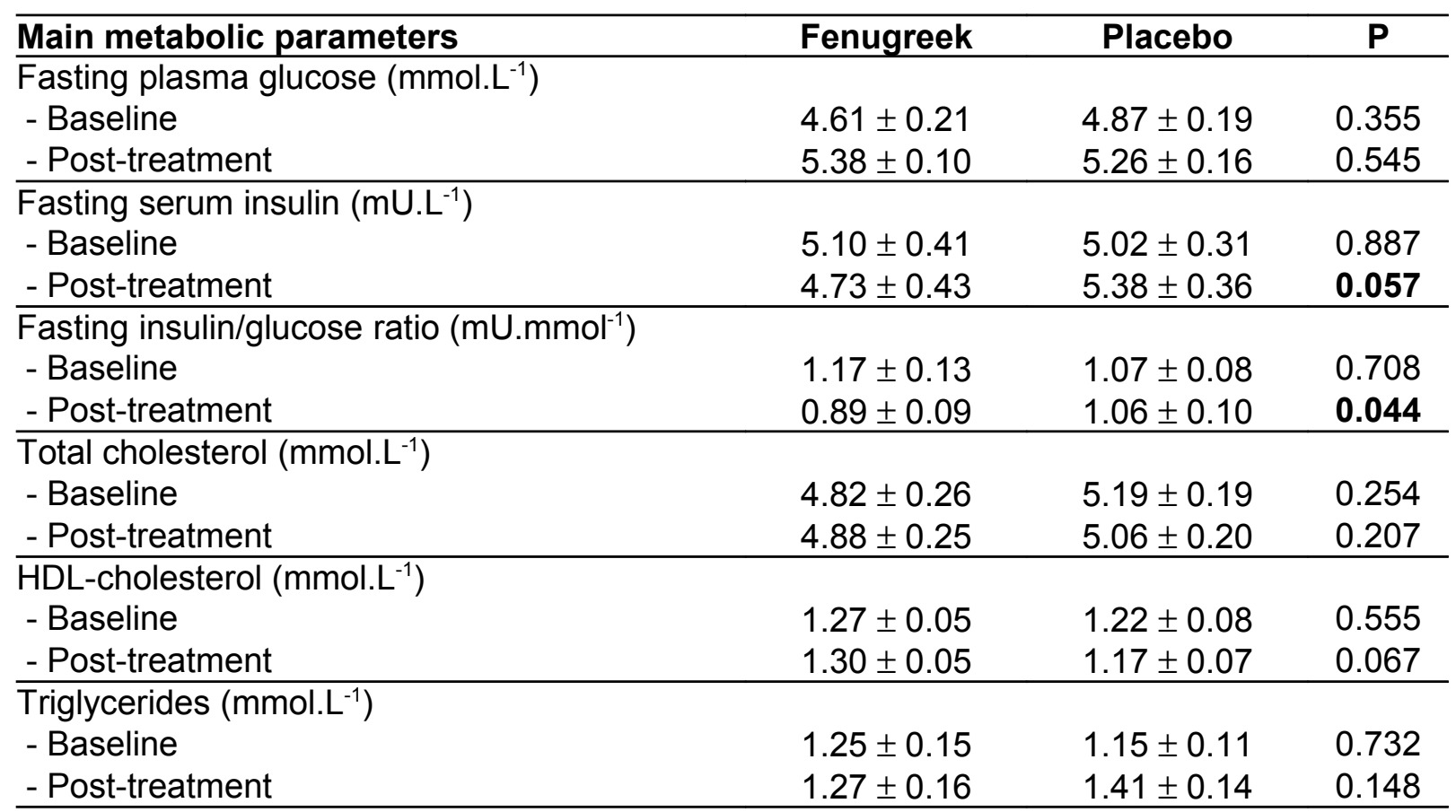


Table II

\begin{tabular}{|c|c|c|c|}
\hline Antioxidant status & Fenugreek & Placebo & $\mathbf{P}$ \\
\hline \multicolumn{4}{|c|}{ Total plasma antioxidant capacity $\left(\mathrm{mmol}^{\mathrm{L}} \mathrm{L}^{-1}\right)$} \\
\hline - Baseline & $1.48 \pm 0.03$ & $1.51 \pm 0.03$ & 0.572 \\
\hline - Post-treatment & $1.51 \pm 0.04$ & $1.49 \pm 0.04$ & 0.138 \\
\hline \multicolumn{4}{|c|}{ LDL susceptibility to oxidation : lag phase time (min) } \\
\hline - Baseline & $16.2 \pm 1.7$ & $15.5 \pm 0.8$ & 0.826 \\
\hline - Post-treatment & $15.3 \pm 0.6$ & $14.8 \pm 0.7$ & 0.546 \\
\hline \multicolumn{4}{|c|}{ LDL susceptibility to oxidation : slope of the propagation phase (OD. $\left.\min ^{-1}\right)$} \\
\hline - Baseline & $0.017 \pm 0.001$ & $0.018 \pm 0.001$ & 0.419 \\
\hline - Post-treatment & $0.018 \pm 0.001$ & $0.020 \pm 0.001$ & 0.264 \\
\hline \multicolumn{4}{|c|}{ LDL susceptibility to oxidation : maximal propagation rate (OD. $\left.\min ^{-1}\right)$} \\
\hline - Baseline & $0.019 \pm 0.001$ & $0.020 \pm 0.001$ & 0.339 \\
\hline - Post-treatment & $0.020 \pm 0.001$ & $0.021 \pm 0.001$ & 0.647 \\
\hline \multicolumn{4}{|c|}{ LDL susceptibility to oxidation : half-time of maximum diene formation (min) } \\
\hline - Baseline & $35.4 \pm 2.6$ & $34.9 \pm 1.2$ & 0.788 \\
\hline - Post-treatment & $33.9 \pm 1.0$ & $34.1 \pm 1.4$ & 0.877 \\
\hline \multicolumn{4}{|c|}{ Serum vitamin $E\left(\mu \mathrm{mol} . \mathrm{L}^{-1}\right)$} \\
\hline - Baseline & $27.9 \pm 1.6$ & $27.3 \pm 0.9$ & 0.752 \\
\hline - Post-treatment & $28.1 \pm 1.8$ & $27.7 \pm 1.2$ & 0.870 \\
\hline \multicolumn{4}{|c|}{$\overline{\mathrm{LDL}}$ vitamin $\mathrm{E}\left(\mathrm{mg} \cdot \mathrm{L}^{-1}\right.$ of $\left.\mathrm{LDL}\right)$} \\
\hline - Baseline & $10.9 \pm 0.9$ & $12.3 \pm 0.6$ & 0.210 \\
\hline - Post-treatment & $12.4 \pm 1.1$ & $11.8 \pm 0.77$ & 0.220 \\
\hline \multicolumn{4}{|c|}{$\overline{\text { Plasma vitamin } C\left(\mu \mathrm{mol} \mathrm{L}^{-1}\right)}$} \\
\hline - Baseline & $42.2 \pm 4.0$ & $52.7 \pm 4.1$ & 0.071 \\
\hline - Post-treatment & $43.9 \pm 4.0$ & $52.1 \pm 4.3$ & 0.762 \\
\hline \multicolumn{4}{|c|}{ Plasma malonyldialdehyde $\left(\mu \mathrm{mol} \mathrm{L}^{-1}\right)$} \\
\hline - Baseline & $0.89 \pm 0.07$ & $0.85 \pm 0.05$ & 0.758 \\
\hline - Post-treatment & $0.85 \pm 0.06$ & $0.82 \pm 0.05$ & 0.841 \\
\hline \multicolumn{4}{|c|}{ Urine F2-isoprostanes/creatinine (pmol.mmol$\left.{ }^{-1}\right)$} \\
\hline - Baseline & $307 \pm 31$ & $478 \pm 55$ & 0.004 \\
\hline - Post-treatment & $357 \pm 54$ & $510 \pm 82$ & 0.704 \\
\hline \multicolumn{4}{|c|}{ Plasma advanced glycation end products } \\
\hline - Baseline & $13887 \pm 982$ & $12302 \pm 445$ & 0.261 \\
\hline - Post-treatment & $12737 \pm 697$ & $12204 \pm 478$ & 0.804 \\
\hline \multicolumn{4}{|c|}{ Plasma advanced oxidation protein products $\left(\mu \mathrm{mol} . \mathrm{L}^{-1}\right)$} \\
\hline - Baseline & $57.9 \pm 5.5$ & $61.4 \pm 3.4$ & 0.592 \\
\hline - Post-treatment & $54.0 \pm 6.9$ & $61.6 \pm 5.3$ & 0.504 \\
\hline
\end{tabular}


Figure 1

A

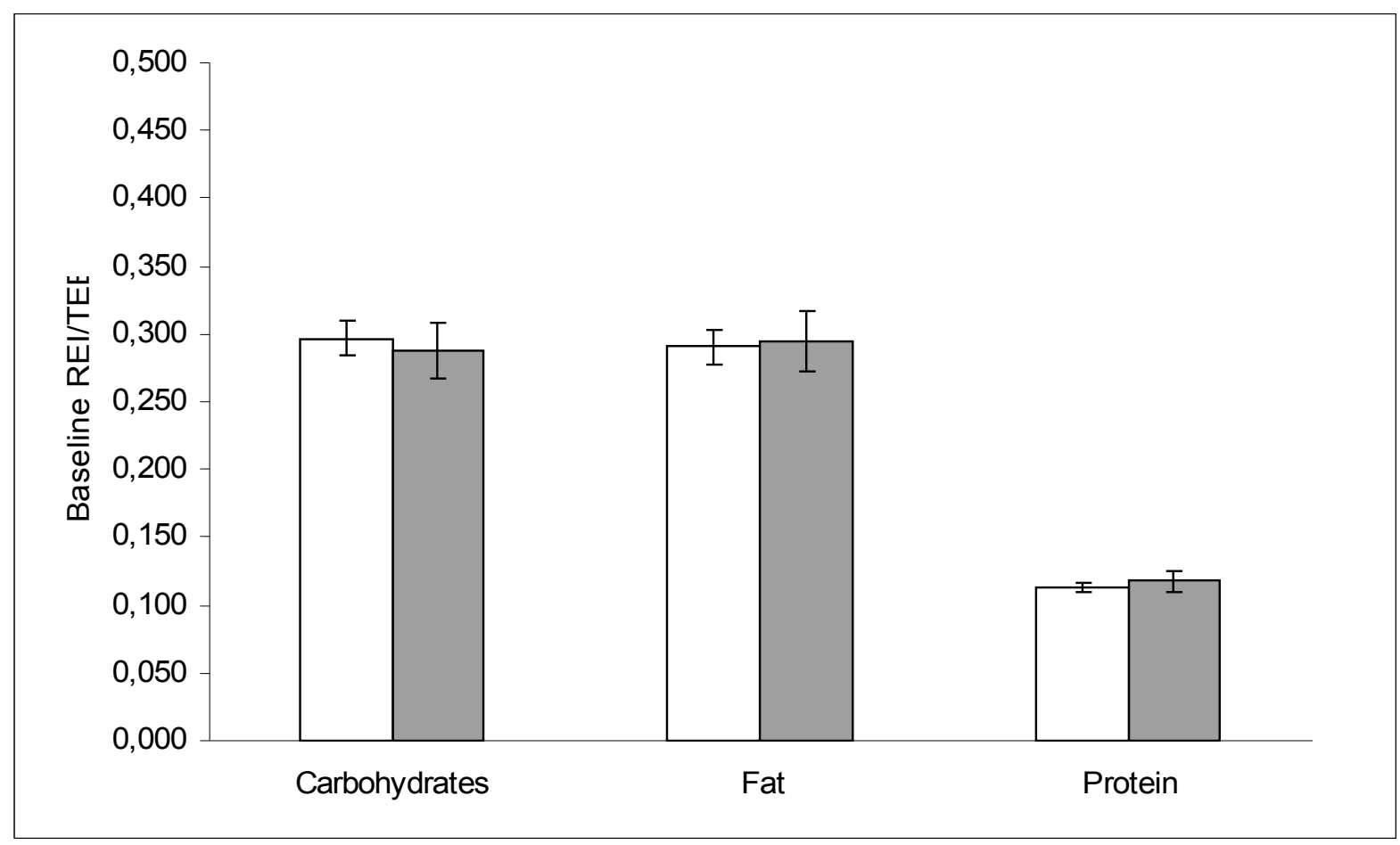

B

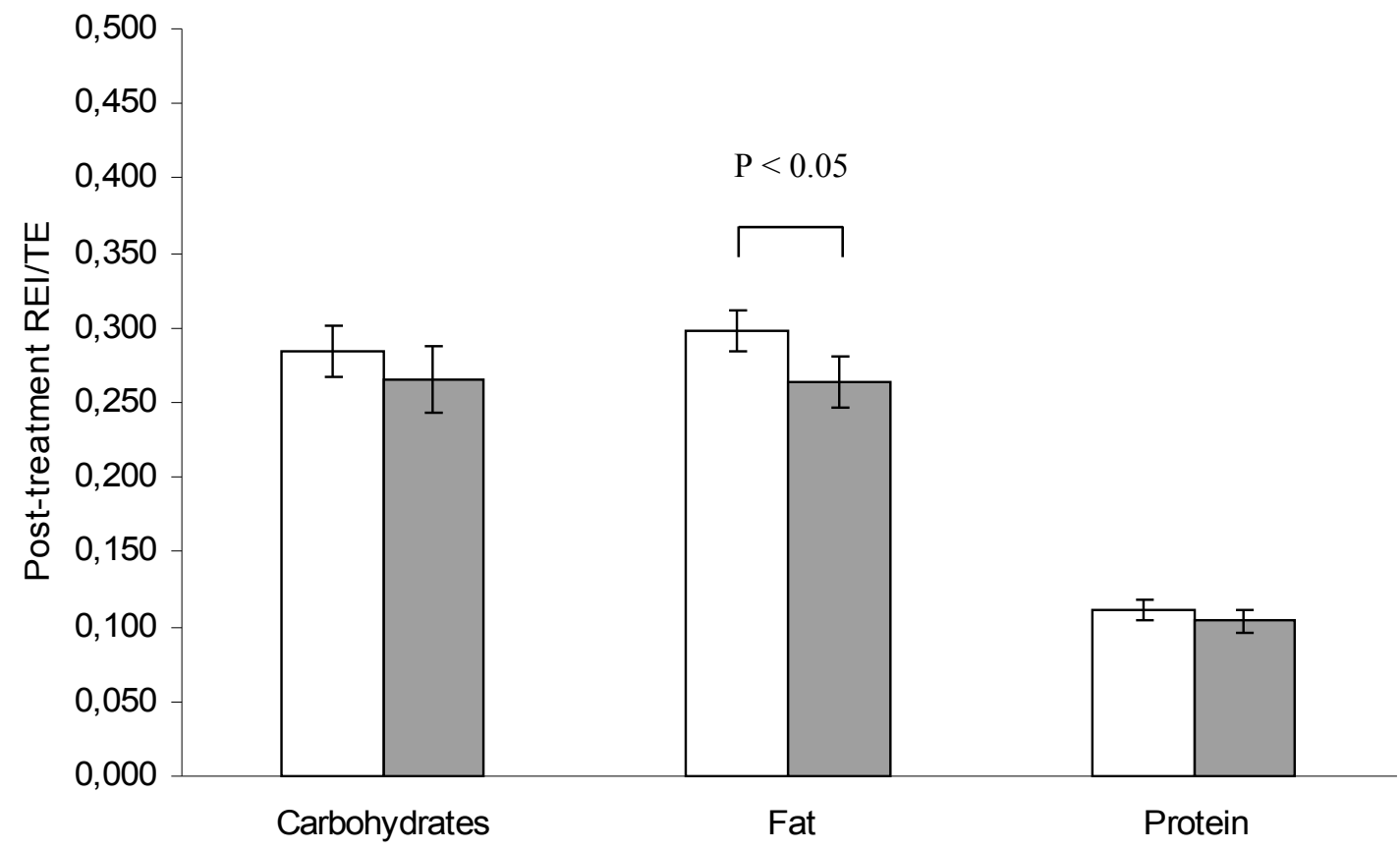




\section{Legends}

\section{Figure 1}

Ratio energy intake/energy expenditure (REI/TEE) recorded by overweight healthy subjects in free-living conditions, before treatment (baseline data, panel A), and during the 7 last days of the 6-week treatment period (post-treatment data, panel B) for placebo group (white bars) and fenugreek seeds extract $1176 \mathrm{mg} /$ day group (striped bars)

\section{Table I}

Comparison of fasting data of plasma glucose, serum insulin and lipid profile between fenugreek seed extract $1176 \mathrm{mg} /$ day and placebo in overweight subjects

\section{Table II}

Comparison of antioxidant status between fenugreek seed extract $1176 \mathrm{mg} /$ day and placebo in overweight subjects 